\title{
Guía de transición ecosocial y principios éticos para nuestros medios
}

\author{
Autores: Manuel Chaparro Escudero, Lara Espinar Medina, Amal El \\ Mohammadiane Tarbift y Lidia Peralta García \\ Título: Guía de transición ecosocial y principios éticos para nuestros medios \\ Año: 2020 \\ Ciudad: Madrid \\ Editorial: Fragua \\ ISBN: 978-84-7074-862-2 \\ 272 págs..
}

Las sociedades occidentales están inmersas en una grave crisis civilizatoria a la que se han visto abocadas como consecuencia de la cultura del desarrollo que prioriza intereses mercantiles, ignorando la profunda vinculación del ser humano con los sistemas naturales. Asimismo, se han impuesto desde élites económicas e intelectuales imaginarios y representaciones simbólicas, difundidas especialmente a través de los medios masivos de información, que han establecido el marco desde el que observar y comprender nuestra realidad, silenciando o menospreciando paralelamente determinados escenarios sociales.

Todo ello tiene lugar y es catalizado desde las coordenadas de una sociedad del espectáculo, que tal y como describía Guy Debord (2002) o Joan Ferrés (2008), prima la instantaneidad, la hegemonía de la apariencia, la rapidez o lo trivial; caracterizada por informaciones de rápida digestión que prefieren la casualidad sobre la causalidad, la fascinación sobre el discernimiento, la preponderancia de la imagen sobre el texto. Los ecos de la metáfora de la modernidad líquida que relataba Zygmunt Bauman (2017) resuenan de este modo una vez más en el terreno de la comunicación dando lugar a un periodismo líquido, dominado por los grandes oligopolios mediáticos, centrado en lo banal y dedicado a distraer a la ciudadanía del debate real.

Pero es precisamente la misma comunicación la que puede actuar de revulsivo y buscar nuevas fórmulas que, desde el desempeño del periodismo en los medios audiovisuales y en las prácticas de transmedialidad, narre a través de una serie de principios éticos información de actualidad con un tratamiento adecuado y reflexivo. A esta tarea se dedica esta obra colectiva en forma de guía práctica y que consideramos de inestimable valor para todo profesional de la 
comunicación en la sociedad del siglo XXI y que tiene en Claves para repensar los medios y el mundo que habitamos: la distopía del desarrollo (Chaparro, 2015) el complemento teórico idóneo.

Capitaneada por Manuel Chaparro Escudero - periodista y Doctor en Comunicación así como Catedrático de Periodismo en la Universidad de Málaga (España) - , esta guía se une a la remarcable producción académica de este intelectual español que siempre ha defendido la comunicación como proceso democrático, considerando a los medios de comunicación locales como herramientas necesarias para descolonizar imaginarios y construir una agenda informativa renovada que vela genuinamente por el bien común.

La guía de transición ecosocial y principios éticos defiende un periodismo lento, pausado, que permite entender e interpretar, que define los porqués y alienta el análisis. Periodistas que abordan las causas de la noticia desde perspectivas históricas, antropológicas, económicas, sociales, políticas y filosóficas. En definitiva, esta es una concepción de la labor informativa que defiende una verdadera comunicación, la cual busca el intercambio de ideas, la horizontalidad, la participación y que presenta en todo momento una actitud democrática, cuyo fin principal es empoderar a la ciudadanía. En síntesis, un modelo de comunicación que se fundamenta en el desarrollo de competencias que persiguen utilidades sociales y valores.

De este modo, se recoge en este completo libro de consulta cinco bloques que tratan temas de debate fundamentales, indicando con claridad y concisión las claves y recomendaciones para atenderlos desde la comunicación con una atención renovada, favoreciendo nuevas narrativas: transición ecosocial contaminación del aire, transición energética, industria de la moda, consumo de carne, etc.-; discursos de odio - lenguaje y estereotipos sexistas, violencia machista, colectivo LGTBI, etc.--; migraciones y minorías - lenguaje contra los discursos de odio, información sobre menores de edad, etc.-; y por último, el adecuado tratamiento informativo de la discapacidad. El volumen se completa con una guía de redacción en forma de anexo, un glosario de términos y recomendaciones bibliográficas.

La comunicación en todas sus vertientes y definiciones debe favorecer el empoderamiento, ayudar al público a conocer el entorno y ponerlo en contacto con los actores sociales que son verdaderos protagonistas de la realidad cotidiana. Esta guía nos ayuda a encontrar esos nuevos relatos que nos permiten abordar y superar con éxito las transformaciones ecosociales necesarias para hacer frente al reto del cambio climático y vencer las injusticias derivadas de la aceptación de un pensamiento y una ideología claramente distópicas. En conclusión, una obra que revitaliza la comunicación y devuelve al periodismo su papel de mediador social con capacidad para generar pensamiento crítico y actuar como contrapoder acercando así la realidad a la ciudadanía.

Javier González de Eusebio 


\section{Referencias bibliográficas}

Bauman, Z. (2017). Modernidad líquida. Ciudad de México: Fondo de Cultura Económica.

Chaparro, M. (2015). Claves para repensar los medios y el mundo que habitamos: la distopía del desarrollo. Bogotá: Ediciones Desde Abajo.

Debord, G. (2002). La sociedad del espectáculo. Valencia: Gallimard.

Ferrés, J. (2008). La educación como industria del deseo. Barcelona: Gedisa. 